\title{
Long-term stocking practices threaten the original genetic diversity of the southernmost European populations of Atlantic salmon Salmo salar
}

\author{
Ana Almodóvar ${ }^{1, *}$, Sheila Leal ${ }^{1}$, Graciela G. Nicola ${ }^{2}$, José Luis Hórreo ${ }^{3}$, \\ Eva García-Vázquez ${ }^{4}$, Benigno Elvira ${ }^{1}$ \\ ${ }^{1}$ Department of Biodiversity, Ecology and Evolution, Complutense University of Madrid (UCM), Madrid 28040, Spain \\ ${ }^{2}$ Department of Environmental Sciences, University of Castilla-La Mancha (UCLM), Toledo 45071, Spain \\ ${ }^{3}$ Department of Biodiversity and Evolutionary Biology, National Museum of Natural Sciences (MNCN), \\ Spanish National Research Council (CSIC), Madrid 28006, Spain \\ ${ }^{4}$ Department of Functional Biology, University of Oviedo, Oviedo 33003, Spain
}

\begin{abstract}
Many Atlantic salmon Salmo salar populations in Europe are threatened by previous stocking with foreign hatchery strains. Temporal patterns of genetic characteristics of salmon from northern Spain, the southernmost European populations, were compared before and after species decline and heavy stocking with specimens from northern Europe. Eleven microsatellite loci were analysed in archival (scales from 1958-1960) and contemporary (2007-2008) samples from the River Sella. Temporal analyses revealed a similar heterozygosity between archival and contemporary samples, despite a drastic decrease in population abundance, while the contemporary sample showed a higher allelic richness due to the occurrence of foreign alleles. Considering only the alleles with at least $4 \%$ frequency in the archival sample, 2 alleles exclusive to the River Sella were absent in the contemporary sample, and 14 alleles showed a decrease of at least $4 \%$ frequency. Four alleles common in Scotland showed a high occurrence in the contemporary sample, so they are good candidates as markers of introgression of foreign genes. The heavy stocking with non-native Scottish broodstocks between 1970 and 1990 caused the introgression found in the contemporary sample when compared with the pristine population. An abrupt decrease was evident when the estimates of effective number of breeders were adjusted to take into account overlapping generations $\left(\mathrm{Nb}_{\mathrm{Adj}}\right)$, effective population size $\left(N \mathrm{~N}_{\mathrm{Adj}}\right)$ estimated from $N \mathrm{Jb}_{\mathrm{Adj}}$, and number of breeders estimated using the sibship assignment method $\left(N \mathrm{~b}_{\mathrm{SIB}}\right)$. The very low effective size values found in the contemporary sample, together with the detrimental synergy between genetic drift and high rates of introgression, represent a severe risk for the conservation of native salmon.
\end{abstract}

KEY WORDS: Conservation genetics - Effective population size • Foreign stocking • Genetic variability · Introgression · Population genetics · Salmonidae

\section{INTRODUCTION}

Preventing the loss of genetic diversity is essential for the conservation and long-term preservation of species, because high genetic diversity is a requisite for evolutionary adaption to ongoing rapid environmental change (Schindler et al. 2010). Increasing temperatures due to global warming influence the

\footnotetext{
${ }^{*}$ Corresponding author: aalmodovar@bio.ucm.es
}

distribution and variation of genetic diversity within and among natural populations (Jonsson \& Jonsson 2009, Hórreo et al. 2014a, Almodóvar et al. 2019). Global warming affects the gene flow across populations because it reduces connectivity; this anthropogenic alteration is more relevant in peripheral populations because the loss of their genetic diversity makes them more prone to local extinctions due to

() The authors 2020. Open Access under Creative Commons by Attribution Licence. Use, distribution and reproduction are unrestricted. Authors and original publication must be credited. 
increasing vulnerability to demographic and environmental stochastic events (Hórreo et al. 2011a, Almodóvar et al. 2012).

One of the current challenges in conservation biology is to maintain the genetic diversity of species and preserve the possible occurrence of local adaptations. The analysis of population genetic structure based on archival and contemporary samples provides a long-term perspective of the evolutionary and demographic changes experienced by the population, which optimizes conservation strategies (García de Leániz et al. 2007).

Atlantic salmon Salmo salar is an anadromous species with a strong homing behaviour, which makes it especially vulnerable to habitat degradation in its natal streams, mainly due to dams, water extraction and pollution (Almodóvar et al. 2019). Human-induced changes in water temperature or quality, overfishing, and alterations in fluvial connectivity may result in steep reductions in populations as well as modifications of population structure (Hórreo et al. 2014a). Another consequence of returning to their natal rivers is the minimal genetic flow among local populations, so salmon that inhabit neighbouring rivers are to a large degree reproductively isolated. This isolation facilitates the genetic differentiation among wild Atlantic salmon populations (Ayllón et al. 2006) and creates the potential for local adaptation (Ciborowski et al. 2007).

In recent decades, Atlantic salmon has suffered a severe decline, becoming extinct in many rivers, with this decline being particularly alarming in southern Europe (Campos et al. 2008). One of these rivers is the River Sella, which supports one of the largest salmon populations of Spain. Catches of returning salmon by recreational fishing started to decline in the mid-1970s and reached the lowest levels in the last decade (Nicola et al. 2018). This trend has been observed throughout northern Spain, including in the nearest neighbours of the Sella, where the conservation status of Atlantic salmon is considered as nonvulnerable in only 4 out of 32 salmon rivers (WWF 2001). Additionally, this decline has been accompanied by alterations in the biology of the species in northern Spain, such as a reduction in the average size and age of returning adults, a delay in river entry, changes in genetic structure and reduction of the river area used by the species (A. Almodóvar, unpubl. data). This raises an obvious conflict in salmon conservation, and the urgent need to negotiate the trade-off between the risk of losing the genetic diversity of local populations and the exploitation of fisheries and the species' habitat.
Different efforts have been made to stop the decline of Atlantic salmon populations, such as stocking, native supportive breeding and habitat restoration. However, these actions should be preceded by an accurate genetic study of the populations. For example, stocking may initially increase the local genetic diversity but the introduction of a foreign genome into a wild native population could damage local adaptations (García de Leániz et al. 2007).

The salmon stocking programs in Spain, based on native fish, began in the early twentieth century. In the study area, all breeders came from local rivers, including the River Sella, and the alevins used for stocking were reared in local fish farms and released annually in all salmon rivers (between 100000 and 300000 alevins). However, over time these practices changed, and heavy stockings of salmon imported from northern Europe were performed in Spanish rivers between the 1970s and 1990s, although they failed in their primary purpose of increasing the census population size (Ciborowski et al. 2007, Campos et al. 2008). Fertilized eggs were imported mainly from Scotland to supplement rivers in the study area. They were reared in fish farms until the alevin stage, when they were released (between 20000 and $100000)$ annually at similar densities in all rivers.

The use of native supportive breeding to preserve genetic diversity and possible local adaptations of populations has been recognized worldwide. However, as has previously been seen, this action can cause both genetic and diversity losses if it is not well monitored and planned (Hórreo et al. 2012).

Some authors have described the loss of genetic integrity in native Atlantic salmon populations due to the introgression produced by farmed escapees in the wild and by the practice of stocking with foreign specimens (Perrier et al. 2013a,b, Le Cam et al. 2015, Glover et al. 2012, 2017, Lehnert et al. 2019, Sylvester et al. 2019). Cross-breeding of stocked individuals with natives should reduce the genetic integrity of the wild population and, if the pressure of invasion continues, there should be a decrease in general population fitness (Sylvester et al. 2019). The loss of native alleles throughout generations also implies the appearance of less adapted individuals. This process of replacement of native alleles may have contributed to the current population declines, since natural selection operates against introgressed individuals (Almodóvar et al. 2006). In the case of Atlantic salmon there are not enough long-term comparative studies, since temporal analyses usually include short time intervals (Ayllón et al. 2006). 
The primary aim of the present work was to assess and quantify any changes in the genetic diversity of the Atlantic salmon population from the River Sella from the 1950s until the 2000s using microsatellite loci. The uniqueness of this temporal comparison is the use of archival scales collected before the stocking practices began, which provide an exceptional source to infer the demographic history of wild salmon populations in its southernmost distribution over 50 yr. Temporal analyses with microsatellite loci have been commonly employed to obtain information about temporal genetic variation because they allow identification of human impacts on populations in terms of introgression, structure and genetic diversity, as well as variations in the effective population size (e.g. Hórreo et al. 2011b, 2014a). Three questions were tested with respect to the results of stocking practices: (1) Has the stocking of foreign specimens changed the genetic variability parameters of Atlantic salmon populations? (2) Is there any loss of native alleles? (3) Is there any significant decline in demographic parameters such as the effective number of breeders $(\mathrm{Nb})$, effective population size $(\mathrm{Ne})$ and their ratio to census size $\left(N_{\mathrm{C}}\right)$ ?

\section{MATERIALS AND METHODS}

\subsection{Study population}

The River Sella is among the most important basins for salmon fishing in northern Spain and supports one of the largest Atlantic salmon Salmo salar populations in the Iberian Peninsula. It is a Site of Community Importance (Code ES1200032) within the Habitats Directive (92/43/EEC), and contributes to the conservation of European freshwater ecosystems. The River Sella is almost free from human alterations, whereas in other southern rivers, multiple anthropogenic stressors can confound or mask interpretations of the natural changes salmon populations may be experiencing.

The analysis includes a sample of the archival River Sella population, represented by dried scales from 172 Atlantic salmon returned after 2 winters at sea (MSW), caught by recreational fishing and collected by the National Inland Fishing and Hunting Service of the Ministry of Agriculture of Spain in 1958 to 1960 (hereafter referred to as 'archival sample'). In addition, 146 contemporary samples of adipose fin clips of returning adults collected in 2007 and 2008 (hereafter referred to as 'contemporary sample') were included for comparing with the archival data.
A baseline of Atlantic salmon microsatellites recently developed for the Eastern Atlantic (SALSEA, Gilbey et al. 2018) was used to identify the possible introgression of northern European fish currently present in the contemporary sample. We exclusively used the baseline for Atlantic salmon from Scottish origin (hereafter referred to as 'Scottish broodstocks'), because most individuals used for massive stocking in the River Sella shared this origin.

\subsection{Molecular analyses}

Genomic DNA was extracted from archival scales using the QIAamp DNA Mini Kit (QIAGEN, IZASA). DNA from contemporary samples was extracted from fin clips with the Chelex resin protocol (Estoup et al. 1996). The quality and concentration of DNA was determined by spectrophotometry and was verified by $0.8 \%$ agarose gel electrophoresis. Eleven microsatellite loci were analysed: Ssa85, Ssa197, Ssa202 (O'Reilly et al. 1996), SSOSL85, SSOSL311, SSOSL417 (Slettan et al. 1995), SSOSL438 (Slettan et al. 1996), SsaF43 (Sánchez et al. 1996), SSspG7, SSsp1605 and SSsp2210 (Paterson et al. 2004). For each locus, polymerase chain reaction (PCR) was performed in a volume of $25 \mu \mathrm{l}$. PCR reactions contained 1.5-2.5 mM $\mathrm{MgCl}_{2}, 1 \times \mathrm{Mg}$-free PCR buffer, $200 \mu \mathrm{M}$ of dNTPs, $0.16 \mathrm{mM}$ of each primer, 1-1.25 U of HotSplit DNA polymerase (Biotools) and 50-100 ng genomic DNA template. Specific annealing temperatures for the loci were $42^{\circ} \mathrm{C}$ (SSsp1605), $50^{\circ} \mathrm{C}$ (SSOSL85, SSOSL311), $53^{\circ} \mathrm{C}$ (SSOSL417, SSOSL438), 55 ${ }^{\circ} \mathrm{C}$ (SsaF43, SSspG7) and $58^{\circ} \mathrm{C}$ (Ssa85, Ssa197, Ssa202, SSsp2210).

The amplifications were performed using the following conditions depending on the primers: $95^{\circ} \mathrm{C}$ for $5 \mathrm{~min}, 30-40$ cycles of $95^{\circ} \mathrm{C}$ for $20-40 \mathrm{~s}, 42^{\circ} \mathrm{C}$ up to $58^{\circ} \mathrm{C}$ for $20-40 \mathrm{~s}$ and $72^{\circ} \mathrm{C}$ for $20-40 \mathrm{~s}$, with a final extension at $72^{\circ} \mathrm{C}$ for $10 \mathrm{~min}$. PCR products were visualized on an ABI PRISM 3730 sequencer (Applied Biosystems), and allele scoring was performed manually with the Peak ScannerTM Software v1.0 (Applied Biosystems). All procedures with archival and contemporary samples were kept separate and performed at different times. The preparation of the buffer solutions, DNA extraction and PCR amplification were all performed in a laminar flow hood. The work area and the equipment were cleaned with UV light followed by ethanol before work on the next step was started, and strict cleaning procedures were respected by all staff. Negative and positive controls were applied in all steps of the extraction and genotyping process. Finally, multiple extractions and PCR 
from the same archival and contemporary samples were undertaken at different times.

\subsection{Data analyses}

MICRO-CHECKER v2.2.3 (Van Oosterhout et al. 2004) was used to assess the frequency of null alleles and scoring errors due to stuttering or large allelic drop-out. The combined use of 2 or 3 methods is the best strategy for minimizing the false-positive and false-negative rates (Dąbrowski et al. 2014). For this reason, 2 different analysis methods were used in addition to test for the presence of null alleles: CERVUS v3.0.3 (Kalinowski et al. 2007) and MLNullFreq (Kalinowski \& Taper 2006).

Tests for Hardy-Weinberg equilibrium and linkage disequilibrium were carried out for each locus and sample with the software GENEPOP v4.1 (Rousset 2008). Allele frequencies, number of alleles, observed $\left(H_{\mathrm{o}}\right)$ and expected $\left(H_{\mathrm{e}}\right)$ heterozygosity were calculated at the population level with GENETIX v4.05.2 (Belkhir et al. 2004). FSTAT v2.9.3 (Goudet 1995) was used to compute allelic richness $\left(A_{R}\right)$ as well as the genetic differentiation $\left(F_{\mathrm{ST}}\right)$ between temporal samples (10000 permutations). Differences in heterozygosity and allelic richness between archival and contemporary samples were analysed by chisquare test using STATISTICA v8.0. Estimation of Wright's fixation indices for the deviation of intratemporal samples from Hardy-Weinberg expectations for heterozygote disequilibrium $\left(F_{\mathrm{IS}}\right)$ were estimated using GENETIX v4.05.2 software. Locus by locus analysis of molecular variance (AMOVA) between temporal samples was performed using ARLEQUIN v3.5 (Excoffier \& Lischer 2010).

Full-sib relationships in archival and contemporary samples were estimated using COLONY v2.0.6.5 (Jones \& Wang 2010) assuming a Full Likelihood (FL) method with female and male polygamy allowed. An empirical range of genotyping error rates $(0.4$ to $3.2 \%$ across loci) was used for each population (see Table A1 in the Appendix).

Evidence for a demographic bottleneck was examined using 2 approaches. First, heterozygosity excess was analysed in the archival and contemporary samples using BOTTLENECK v1.2.02 (Piry et al. 1999), assuming a 2-phase mutation model (TPM) with percentages of 70,80 and $90 \%$ in the stepwise mutation model, a variance of 12 among multiple steps and 10000 iterations. Significance of heterozygous excess was statistically tested with a 1-tailed Wilcoxon's signed-rank test. In addition, we estimated the ratio of the number of alleles to the range in allele size $(M$ ratio) using the M_P_VAL software as described by Garza \& Williamson (2001). This was compared to a critical value of $M(M \mathrm{c})$ from a theoretical population in mutation-drift equilibrium, using the CRITICAL_M software (Garza \& Williamson 2001), assuming prebottleneck effective population sizes of 50, 100, 500 and 1000 and a mutation rate $(\mu)$ of $5 \times 10^{-4}$. Following the recommendations of Peery et al. (2012), the proportion of 1-step mutations (pg) was set to 0.22 and the mean size of non-1-step mutations $(\Delta \mathrm{g})$ to 3.1 .

To asses introgression of Scottish broodstocks in our archival and contemporary Sella samples, the estimation of individual admixture coefficients was performed using the Bayesian clustering method implemented in STRUCTURE v2.3.4 (Pritchard et al. 2000). STRUCTURE analyses were performed for 1 to 10 clusters $(K)$ with 10 replicates for each simulated cluster (burn-in period of 250000 steps and 1000000 Markov chain Monte Carlo [MCMC] sweeps) and applying the admixture model with correlated allele frequencies. Optimal $K$ was determined using STRUCTURE HARVESTER v0.6.94 (Earl \& von Holdt 2012). Replicates were aggregated using CLUMP v1.1.2 (Jakobsson \& Rosenberg 2007) and graphically displayed with DISTRUCT v1.1 (Rosenberg 2004). The threshold values used to assign individuals to parental or admixed classes were derived from the results obtained for Scottish broodstocks. Thus, individuals with $Q$-values between 0 and 0.190 were classified as Scottish broodstock and those with values between 0.811 and 1 as native River Sella, while individuals with $Q$ values between 0.191 and 0.810 were classified as introgressed individuals.

The power of our microsatellite loci for assigning analysed samples to parental or admixed classes was evaluated using 3 metrics after Vähä \& Primmer (2006): efficiency, accuracy and overall performance. To this end, 400 genotypes of parental individuals (200 archival River Sella and 200 Scottish broodstock), 200 backcrosses between parental individuals from both origins (F1), 200 backcrosses of F1 (F2) and 200 backcrosses of F1 with each parental individual were generated in HYBRIDLAB v1.0 (Nielsen et al. 2006). Simulated individuals were analysed using STRUCTURE v2.3.4, with the a priori assumption of 2 groups $(K=2)$ corresponding to native River Sella and Scottish broodstocks. Ten replicates, an admixture model with correlated allele frequencies and a burn-in period of 250000 steps and 1000000 MCMC sweeps were performed. These simulated individuals were classified as parental or admixed classes (F1, F2 and backcrosses 
of F1) according to the threshold $Q$-value of 0.810 to estimate the efficiency, accuracy and overall performance of these assignments.

Principal coordinates analysis (PCoA) was computed to explore the allelic divergence among populations oin the multivariate space using GenAlEx v6.5 (Peakall \& Smouse 2012). PCoA was computed from the genetic distance calculated across multiple loci for each pair of individuals in the GenAlEx software.

Estimates of census size (NC) for the archival (1950s period) and contemporary (2000s period) samples were determined by the harmonic mean from 10 years of catches of anadromous adults from the River Sella collected by local management authorities. These estimates were corrected considering that catches throughout the fishing period may vary between 20 and $40 \%$ of the total salmon population inhabiting a river (Ribeiro et al. 2008). Effective number of breeders over a reproductive year $\left(N b_{\mathrm{LD}}\right)$ was calculated for each period (1950s and 2000s) using the linkage disequilibrium (LD) method implemented in NeEstimator v.2.1 (Do et al. 2014). A minimum allele frequency cut-off value of 0.02 was employed and $95 \%$ confidence intervals were obtained using the jack-knife method. This approach is based on LD between alleles from neutral loci unlinked within populations with random mating and implements a bias correction under a wide range of sample sizes. This method has shown consistent values across different demographic scenarios and has been shown to be the best method to estimate the effective population size in populations with both low to no migration and small effective population sizes (Gilbert \& Whitlock 2015), and missing data adjustment. Considering a situation of overlapping generations, $\mathrm{Nb}$ estimates can be biased. Despite this, the method developed by Waples et al. (2014) was applied using 2 simple life history traits to adjust genetic estimates of $N b_{\mathrm{LD}}$ for correcting biases due to age structure. This $N b_{\mathrm{LD}}$ was adjusted using the ratio between adult life span (AL) and age at maturity $(\alpha)$ using the following equation:

$$
N b_{\text {Adj }}=N b_{\mathrm{LD}} /(1.103-0.245 \times \log (\mathrm{AL} / \alpha)
$$

$N b_{\text {Adj }}$ can be a more easily quantifiable and useful tool for managers but remains less used than $\mathrm{Ne}$ (Perrier et al. 2016). Adjusted age at spawning has been estimated to be between 2.65 and 3.04 yr in northern Iberian rivers (Consuegra et al. 2005). Considering this range, an average age at maturity of $2.8 \mathrm{yr}$ was assumed for the River Sella. The AL value was calculated as described by Waples et al. (2014) using a maximum breeding age $(\omega)$ of $5 \mathrm{yr}$ for Atlantic sal- mon. $\mathrm{Ne}_{\text {Adj }}$ was calculated using the equation proposed by Waples et al. (2014):

$$
N \mathrm{e}_{\text {Adj }}=N \mathrm{~b}_{\mathrm{Adj}} /(0.485+0.758 \times \log (\mathrm{AL} / \alpha)
$$

In addition, effective population size $\mathrm{Nb}_{\mathrm{SIB}}$ was estimated using the sibship assignment method implemented in COLONY v2.0.6.5 (Jones \& Wang 2010), assuming a random mating population and a 'Known

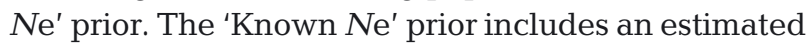
sex ratio of 1.1 (Álvarez et al. 2010) and an estimated $\mathrm{Ne}$ of $10 \%$ of $\mathrm{NC}$, assuming a ratio for $\mathrm{Ne} / \mathrm{NC}$ of 0.1 (Verspoor et al. 2007). $N b_{\text {LD }}$ and $N b_{\text {SIB }}$ estimates were carried out after removing the individuals assigned as admixed in the contemporary samples. The effective size ratios $N b_{\text {Adj }} / N_{C}$ and $N e_{\text {Adj }} / N c$ were also calculated following Perrier et al. (2016).

\section{RESULTS}

\subsection{Genetic variation and introgression analysis}

Eleven microsatellite loci were analysed in archival sample of Atlantic salmon Salmo salar, with an average successful amplification ranging from 88 to $99 \%$ and a variation between PCR replicates of 96 to $100 \%$ depending on the locus. The loci SSOSL438, SsaF43 and Ssa85 proved difficult to amplify in the archival sample, with no allelic information in more than $40 \%$ of the individuals. Thence, these 3 loci were excluded from the analyses and were not amplified in the contemporary sample.

Degradation and the small quantities of DNA in the archival sample could have caused some allelic dropouts, but MICRO-CHECKER analyses (at the Bonferroni confidence level) did not exhibit any evidence of null alleles, large allelic dropout or stuttering. The results from CERVUS showed similar results for this sample, with an intermediate null allele frequency $\left(F_{(\text {null })}<0.05\right)$. However, the analysis of MLNullFreq software indicated a null allele frequency for loci SSOSL417 and SSspG7 that was higher and significant $\left(F_{\text {(null) }} \geq 0.02, \mathrm{p}<0.05\right)$ in the archival sample. For true null alleles, consistency among different methods and temporal populations is expected (Dąbrowski et al. 2014). Thus, the null alleles observed did not justify the elimination of any locus from the data analysis.

A total of 92 alleles from the archival sample and 116 from the contemporary sample were observed in the 8 loci analysed. The number of alleles per locus ranged from 6 to 15 in the archival sample, and from 8 to 23 in the contemporary one (Table 1). The esti- 
Table 1. Genetic diversity indices for the archival and contemporary Atlantic salmon samples from the River Sella: sample size $(N)$, observed number of alleles $(A)$, allelic richness $\left(A_{\mathrm{R}}\right)$, expected $\left(H_{\mathrm{e}}\right)$ and observed heterozygosity $\left(H_{\mathrm{o}}\right), F_{\mathrm{IS}}$ values, deviations from Hardy-Weinberg equilibrium (HWE) and locus by locus analysis of molecular variance $\left(\Phi_{\mathrm{ST}}\right)$. ns: not significant,

$$
{ }^{*} \mathrm{p}<0.05,{ }^{* *} \mathrm{p}<0.01,{ }^{* * *} \mathrm{p}<0.001
$$

\begin{tabular}{|c|c|c|c|c|c|c|c|c|c|}
\hline & \multirow{2}{*}{ Total } & \multicolumn{8}{|c|}{ _ Locus } \\
\hline & & Ssa197 & SSOSL85 & SSOSL311 & SSOSL417 & SSsp2210 & SSspG7 & SSsp1605 & Ssa202 \\
\hline \multicolumn{10}{|c|}{ Archival sample } \\
\hline$N$ & 172 & 165 & 166 & 151 & 171 & 162 & 157 & 153 & 149 \\
\hline$A$ & 11.500 & 15 & 14 & 10 & 15 & 9 & 15 & 6 & 8 \\
\hline$A_{\mathrm{R}}$ & 11.658 & 13.127 & 12.543 & 9.596 & 12.968 & 8.038 & 13.674 & 5.267 & 8.000 \\
\hline$H_{\mathrm{e}}$ & 0.753 & 0.860 & 0.820 & 0.796 & 0.777 & 0.768 & 0.789 & 0.553 & 0.661 \\
\hline$H_{\mathrm{o}}$ & 0.736 & 0.842 & 0.813 & 0.768 & 0.760 & 0.765 & 0.777 & 0.542 & 0.618 \\
\hline$F_{\text {IS }}$ & 0.026 & 0.023 & 0.011 & 0.039 & 0.024 & 0.006 & 0.018 & 0.024 & 0.072 \\
\hline HWE & ns & ns & ns & ns & ns & ns & ns & ns & ns \\
\hline \multicolumn{10}{|c|}{ Contemporary sample } \\
\hline$N$ & 146 & 146 & 140 & 141 & 144 & 145 & 143 & 144 & 146 \\
\hline$A$ & 14.500 & 19 & 12 & 23 & 18 & 10 & 16 & 8 & 10 \\
\hline$A_{\mathrm{R}}$ & 14.283 & 16.239 & 10.713 & 19.381 & 16.762 & 9.559 & 13.041 & 7.287 & 8.989 \\
\hline$H_{\mathrm{e}}$ & 0.799 & 0.864 & 0.787 & 0.883 & 0.870 & 0.783 & 0.768 & 0.647 & 0.786 \\
\hline$H_{\mathrm{o}}$ & 0.789 & 0.863 & 0.729 & 0.879 & 0.875 & 0.759 & 0.811 & 0.628 & 0.767 \\
\hline$F_{\mathrm{IS}}$ & 0.016 & 0.004 & 0.078 & 0.007 & -0.002 & 0.034 & -0.052 & 0.034 & 0.028 \\
\hline HWE & ns & ns & * & ns & ns & ns & ns & ns & ns \\
\hline$\Phi_{\mathrm{ST}}$ & $0.013^{* * *}$ & $0.004^{*}$ & $0.016^{* *}$ & $0.025^{* * *}$ & $0.021^{* * *}$ & $0.005^{*}$ & 0.004 & 0.006 & $0.023^{* *}$ \\
\hline
\end{tabular}

mates of $F_{\mathrm{IS}}$ did not show significant deviation from Hardy-Weinberg equilibrium in the archival sample. In the contemporary sample, a significant $(\mathrm{p}<0.05)$ deviation was detected at the SSOSL85 locus due to deficiency of heterozygotes (Table 1). No evidence of linkage among pairs of loci was observed within the 2 samples.

Heterozygosity was high and stable and did not differ between temporal samples ( $p>0.05)$, despite a drastic decrease in population abundance, as inferred from the pattern of declining rod catches (Fig. 1). However, the number of alleles showed significant temporal heterogeneity between archival and contemporary samples $(\mathrm{p}<0.01$, average $A: 11.5$ in the archival and 14.5 in the contemporary sample). Likewise, a slight tendency of increasing allelic richness was observed over time in the River Sella (average $A_{R}: 11.7$ in the archival and 14.3 in the contemporary sample). These consistent differences in allelic richness were mainly due to the abrupt increase in the allele number at the SSOSL311 locus in the contemporary sample. Similarly, a marked decrease was found at the SSOSL85 locus over time.

Genetic differentiation between the temporal samples was high and signif- icant over loci (average $\Phi_{\mathrm{ST}}=0.013, \mathrm{p}<0.001$ ). Locus-by-locus AMOVA revealed that this differentiation was significant for 6 loci (Table 1).

We analysed the degree of association between the allele frequencies of the archival and contemporary samples, which, as expected, was very high and significant $\left(\mathrm{r}=0.928, \mathrm{r}^{2}=0.86, \mathrm{p}<0.001, \mathrm{n}=132\right)$. It was also significant, but lower, between the archival sample and Scottish broodstocks $\left(\mathrm{r}=0.571, \mathrm{r}^{2}=0.33, \mathrm{p}<\right.$ $0.001, \mathrm{n}=69$ ), while the degree of association was

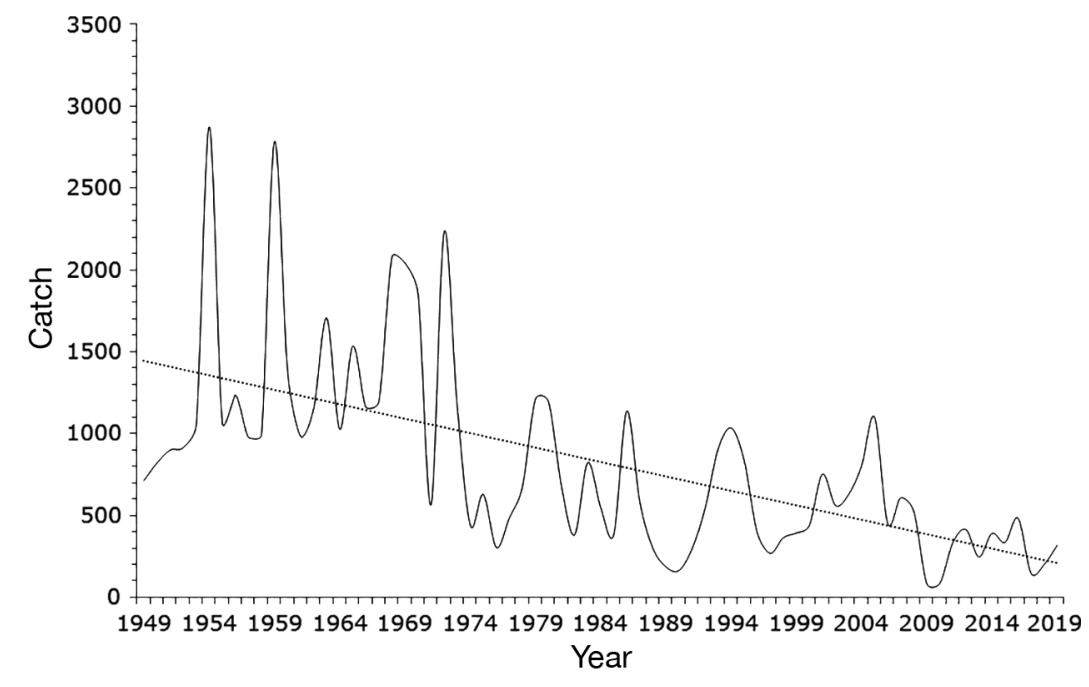

Fig. 1. Long-term changes in total annual catch of Atlantic salmon (number of fish) in the River Sella from 1949 to 2019. The Mann-Kendall test was used to identify a significant negative trend (dotted line $\mathrm{S}=-0.432, \mathrm{p}<0.001$ ) 
higher between the contemporary sample and Scottish broodstocks ( $r=0.657, \mathrm{r}^{2}=0.43, \mathrm{p}<0.001, \mathrm{n}=69$ ), which may be indicative of a higher level of introgression in the contemporary sample.

The variation (increase or decrease) of allele frequencies between archival and contemporary samples was significantly associated with the difference between allele frequencies originally present in the River Sella and in Scottish broodstocks ( $\mathrm{r}=0.646, \mathrm{r}^{2}=$ $0.42, \mathrm{p}<0.001, \mathrm{n}=69$ ). That is, increases were positively correlated with relatively high allele frequencies in Scottish broodstocks, while decreases were correlated with relatively high allele frequencies in the River Sella.

The contemporary sample showed evidence of genetic erosion due to disappearance of native alleles that were present in the archival sample. Regarding the most frequent alleles in the archival sample (i.e. with at least $4 \%$ frequency; Table 2), SSOSL85*194 and SSspG $7^{*} 110$ were not found in the contemporary sample.

Furthermore, 14 alleles of the 8 loci analysed (with at least $4 \%$ frequency) showed a decrease in the contemporary sample (range: $4.12-$ 15.24\%): Ssa197*211, SSOSL85* 190, SSOSL85*218, SSOSL85*220, SSOSL311*125, SSOSL311*147, SSOSL417*157, SSOSL417*171, SS sp2210*126, SSsp2210*162, SSsp G7*118, SSsp1605*222, Ssa202* 240 and $S_{s a 2} 202 * 244$.

In contrast, 3 new alleles were detected in the contemporary sample (with at least $4 \%$ frequency) that had not been observed in the archival sample: SSOSL311*123, SSOSL $417^{*} 179$ and SSsp2210*158.

Likewise, the comparison of allele frequencies between archival and contemporary samples showed an increase higher than 4\% (range: $4.66-8.78 \%$ ) in 10 alleles of 6 loci: SSOSL85*182, SSOSL85*196, SSO SL85*222, SSOSL311*145, SSO SL417*201, SSOSL417*203, SSsp $2210 * 130, S S s p 1605^{*} 242, S$ sa202* 236 and $\operatorname{Ssa}_{202}^{*} 268$. Four of these alleles were also present in relatively high frequencies and were widely distributed in Scotland ac- cording to the SALSEA baseline: SSsp2210*130 (37.16\% of mean frequency in Scotland), SSsp1605* $242(24.97 \%), S_{s a 202 * 236}(12.62 \%)$ and $S_{s a 202 *} 268$ $(5.87 \%)$. Therefore, they are good indicators of introgression of Scottish non-native alleles in native populations.

The level of population genetic differentiation $\left(F_{\mathrm{ST}}\right)$ between temporal samples (archival vs. contemporary) was significant $\left(F_{\mathrm{ST}}=0.011, \mathrm{p}<0.001\right)$ and consistent with the results observed in allelic diversity.

The BOTTLENECK test did not detect significant excess heterozygosity for the TPM model with percentages of 70,80 and $90 \%$ in the stepwise mutation model ( $p>0.05 ;$ Table 3 ). Similarly, $M$-ratio values were not significantly lower than the simulated value of $M c$ under mutation-drift equilibrium for the lower

Table 2. Comparison of mean allele frequencies $(\bar{x})$ in \% between archival $(n=172)$ and contemporary $(n=146)$ Atlantic salmon samples from the River Sella. Only alleles with mean allele frequencies higher than $4 \%$ are included. Temporal increase/decrease values $(\Delta)$ and direction of change between both samples are also shown. Mean allele frequencies of these alleles in the original country of stocking (Scotland, SALSEA microsatellite baseline) are also included when available

\begin{tabular}{|c|c|c|c|c|c|c|}
\hline Locus & Allele & $\begin{array}{c}\text { Archival } \\
\text { sample } \\
\qquad \bar{x}\end{array}$ & $\begin{array}{c}\text { Contemporary } \\
\text { sample } \\
\bar{X}\end{array}$ & $\Delta$ & $\begin{array}{l}\text { Direction } \\
\text { of change }\end{array}$ & $\begin{array}{c}\text { Scottish } \\
\text { broodstocks } \\
\overline{\bar{X}}\end{array}$ \\
\hline SSsp1605 & $\begin{array}{l}{ }^{*} 222 \\
{ }^{*} 242\end{array}$ & $\begin{array}{r}58.75 \\
3.75\end{array}$ & $\begin{array}{r}50.34 \\
8.62\end{array}$ & $\begin{array}{l}-8.41 \\
+4.87\end{array}$ & $\begin{array}{l}\downarrow \\
\uparrow\end{array}$ & $\begin{array}{l}20.26 \\
24.97\end{array}$ \\
\hline Ssa197 & ${ }^{*} 211$ & 16.97 & 7.88 & -9.09 & $\downarrow$ & 6.80 \\
\hline Ssa202 & $\begin{array}{l}{ }^{*} 236 \\
{ }^{*} 240 \\
{ }^{*} 244 \\
{ }^{*} 268\end{array}$ & $\begin{array}{r}5.26 \\
33.55 \\
46.71 \\
5.26\end{array}$ & $\begin{array}{l}14.04 \\
24.66 \\
33.22 \\
13.01\end{array}$ & $\begin{array}{r}+8.78 \\
-8.89 \\
-13.49 \\
+7.75\end{array}$ & $\begin{array}{l}\uparrow \\
\downarrow \\
\downarrow \\
\uparrow\end{array}$ & $\begin{array}{r}12.62 \\
15.05 \\
15.63 \\
5.87\end{array}$ \\
\hline SSOSL85 & $\begin{array}{l}{ }^{*} 182 \\
{ }^{*} 190 \\
{ }^{*} 194 \\
{ }^{*} 196 \\
{ }^{*} 218 \\
{ }^{*} 220 \\
{ }^{*} 222\end{array}$ & $\begin{array}{r}23.80 \\
19.88 \\
5.72 \\
2.11 \\
5.42 \\
8.73 \\
2.41\end{array}$ & $\begin{array}{r}32.50 \\
15.36 \\
0.00 \\
10.36 \\
0.36 \\
2.14 \\
8.57\end{array}$ & $\begin{array}{l}+8.70 \\
-4.52 \\
-5.72 \\
+8.25 \\
-5.06 \\
-6.59 \\
+6.16\end{array}$ & $\begin{array}{c}\uparrow \\
\downarrow \\
\text { Lost } \\
\uparrow \\
\downarrow \\
\downarrow \\
\uparrow\end{array}$ & \\
\hline SSOSL311 & $\begin{array}{l}{ }^{*} 123 \\
{ }^{*} 125 \\
{ }^{*} 145 \\
{ }^{*} 147\end{array}$ & $\begin{array}{r}0.00 \\
35.10 \\
14.24 \\
14.90\end{array}$ & $\begin{array}{r}8.87 \\
19.86 \\
19.50 \\
5.32\end{array}$ & $\begin{array}{r}+8.87 \\
-15.24 \\
+5.26 \\
-9.58\end{array}$ & $\begin{array}{c}\text { New } \\
\downarrow \\
\uparrow \\
\downarrow\end{array}$ & \\
\hline SSOSL417 & $\begin{array}{l}{ }^{*} 157 \\
{ }^{*} 171 \\
{ }^{*} 179 \\
{ }^{*} 201 \\
{ }^{*} 203\end{array}$ & $\begin{array}{r}38.60 \\
16.37 \\
0.00 \\
4.39 \\
2.63\end{array}$ & $\begin{array}{r}23.96 \\
7.29 \\
5.56 \\
9.72 \\
7.29\end{array}$ & $\begin{array}{r}-14.64 \\
-9.08 \\
+5.56 \\
+5.33 \\
+4.66\end{array}$ & $\begin{array}{c}\downarrow \\
\downarrow \\
\text { New } \\
\uparrow \\
\uparrow\end{array}$ & \\
\hline SSspG7 & $\begin{array}{l}{ }^{*} 110 \\
{ }^{*} 118\end{array}$ & $\begin{array}{r}4.78 \\
18.79\end{array}$ & $\begin{array}{r}0.00 \\
14.34\end{array}$ & $\begin{array}{l}-4.78 \\
-4.45\end{array}$ & $\begin{array}{c}\text { Lost } \\
\downarrow\end{array}$ & $\begin{array}{r}0.08 \\
11.24\end{array}$ \\
\hline SSsp2210 & $\begin{array}{l}{ }^{*} 126 \\
{ }^{*} 130 \\
{ }^{*} 158 \\
{ }^{*} 162\end{array}$ & $\begin{array}{r}20.68 \\
16.67 \\
0.00 \\
8.95\end{array}$ & $\begin{array}{r}16.21 \\
22.07 \\
7.24 \\
4.83\end{array}$ & $\begin{array}{l}-4.47 \\
+5.40 \\
+7.24 \\
-4.12\end{array}$ & $\begin{array}{c}\downarrow \\
\uparrow \\
\text { New } \\
\downarrow\end{array}$ & $\begin{array}{r}9.97 \\
37.16 \\
1.87 \\
6.91\end{array}$ \\
\hline
\end{tabular}


Table 3. Heterozygosity excess assuming a 2-phase mutation model with percentages of 70,80 and $90 \%$ in the stepwise mutation model (SMM), $M$-ratio and critical value of $M(M \mathrm{c})$ assuming pre-bottleneck effective population sizes $(\mathrm{Ne})$ of $50,100,500$ and 1000 for the archival and contemporary Atlantic salmon samples from the River Sella

\begin{tabular}{|c|c|c|c|c|c|c|c|c|}
\hline \multirow{2}{*}{ Sample } & \multicolumn{3}{|c|}{ Heterozygosity excess $p$-values } & \multirow{2}{*}{$M$-ratio } & \multicolumn{4}{|c|}{$-M_{\mathrm{C}}$} \\
\hline & $70 \% \mathrm{SMM}$ & $80 \% \mathrm{SMM}$ & $90 \% \mathrm{SMM}$ & & $N e=50$ & $N e=100$ & $\mathrm{Ne}=500$ & $\mathrm{Ne}=1000$ \\
\hline Archival sample & 0.844 & 0.973 & 0.986 & 0.746 & 0.758 & 0.750 & 0.712 & 0.705 \\
\hline Contemporary sample & 0.963 & 0.990 & 0.998 & 0.833 & 0.758 & 0.746 & 0.710 & 0.705 \\
\hline
\end{tabular}

and upper values of pre-bottleneck effective population size values ( $p>0.05$; Table 3$)$. Neither test showed any old or recent bottlenecks in the archival or the contemporary sample.

Full-sib relationship analyses detected 166 and 79 families in archival and contemporary samples, respectively. Archival family samples were frequently composed of 1 individual, except 1 family of 3 individuals and 4 of 2 . In the contemporary sample, a similar result was observed, with 1 family of 3 individuals and 10 of 2 individuals.

The assignment efficiency and accuracy of the 5 microsatellite loci in simulated individuals were high, with values ranging from 95 to $100 \%$. When a threshold $Q$-value of 0.810 was used, efficiency and accuracy decreased by $2 \%$ in backcrosses of F1 with archival River Sella parental individuals and by $5 \%$ in backcrosses of F1 with parental Scottish broodstocks. These backcrosses were responsible for the observed decreases in overall performance of 3 and $10 \%$, respectively. Therefore, based on the above and the results obtained for the Scottish broodstock baseline, a threshold of $Q>0.810$ can be used to identify individuals to parental or introgressed classes in natural populations.

The STRUCTURE analysis indicated that the most likely number of clusters was $K=2$ using the Evanno approach. Examination of individual admixture proportions revealed that one cluster corresponded to the archival Sella sample and the other to the Scottish broodstocks. In addition, admixture between the archival Sella sample and Scottish broodstocks was evident in the contemporary Sella sample (Fig. 2).

Results from the admixture analysis were strongly consistent across runs and did not show individual changes in the observed $Q$-values and classes assigned (native, Scottish broodstock or introgressed individuals). The archival sample (native) and Scot-
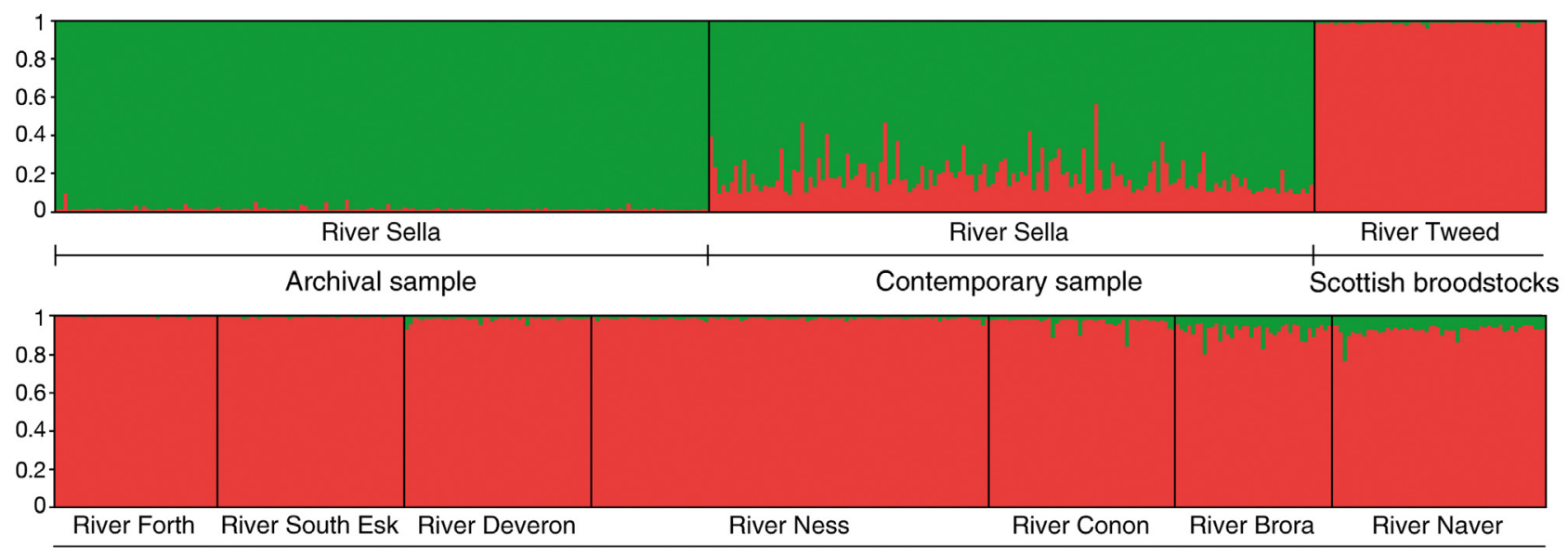

Scottish broodstocks

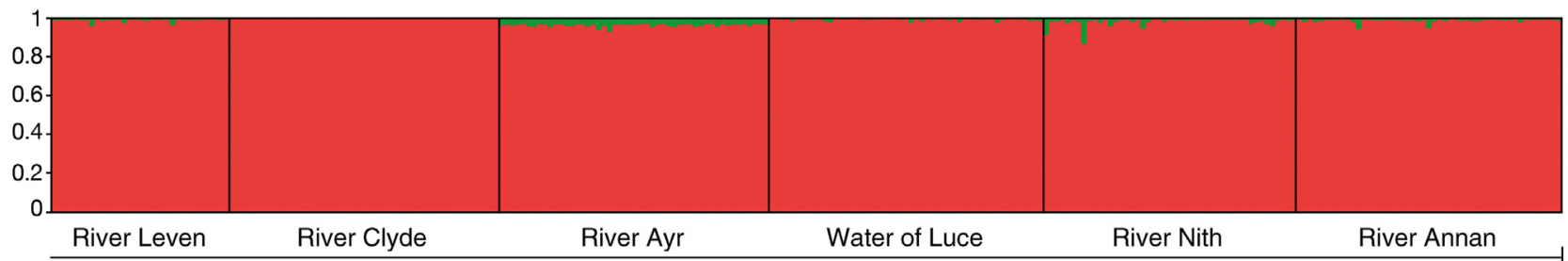

Scottish broodstocks

Fig. 2. STRUCTURE plot for the archival and contemporary samples of the River Sella and putative exotic Scottish broodstock strain Atlantic salmon under the assumption of 2 genetic units $(K=2)$. Vertical bars represent proportions of membership of each individual to each of the 2 clusters 
tish broodstocks showed a high percentage of membership within these 2 clusters (Fig. 2), with average $Q$-values of 0.989 and 0.979 , respectively. Thus, all individuals in the archival Sella sample were nonadmixed, but 55 out of the 146 individuals in the contemporary sample were identified as introgressed from Scottish broodstocks (38\%) with $Q$-values between 0.436 and 0.809 , thereby providing strong evidence of admixture. Furthermore, $33 \%$ of introgressed individuals from the contemporary Sella sample showed admixture proportions exceeding $10 \%$.

The PCA showed a clear separation between the archival Sella sample and Scottish broodstocks, with the contemporary Sella sample being placed between both of them (Fig. 3). These results were consistent with the STRUCTURE analysis and, although the 3

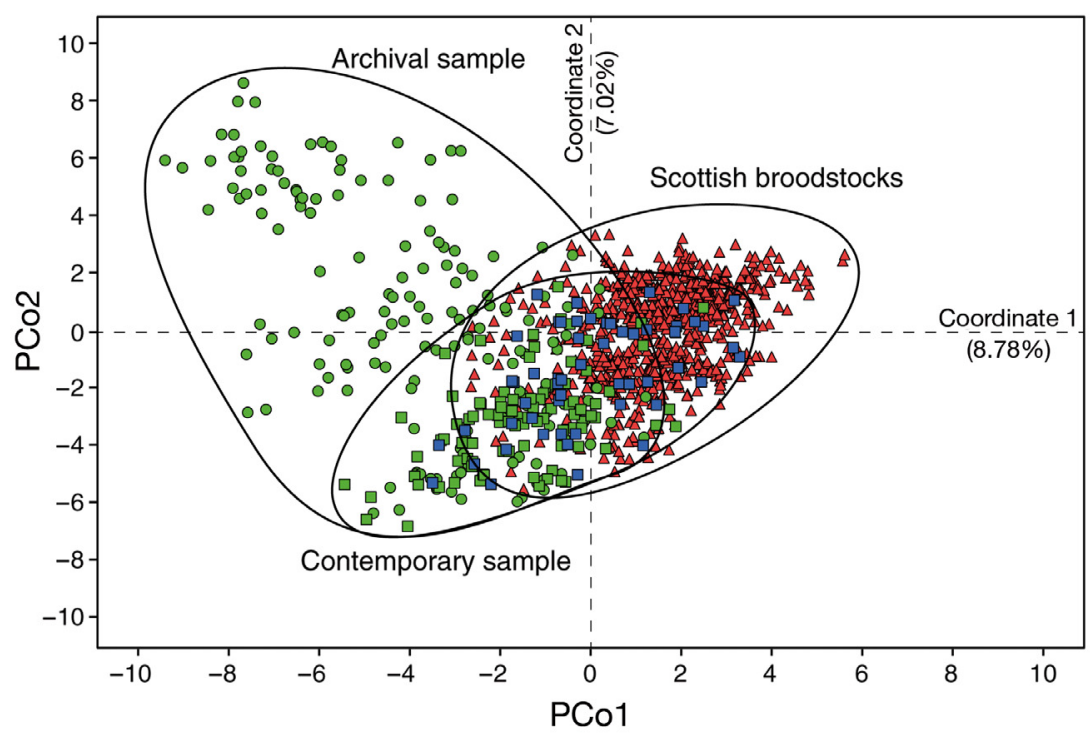

Fig. 3. Principal coordinates analysis for the archival and contemporary samples of the River Sella and Scottish broodstock Atlantic salmon based on microsatellite genotypes. Individuals are colour-coded according to the results of the admixture analyses: (green) pure archival Sella sample ( $Q$-value $>0.811)$; (red) Scottish broodstocks ( $Q$-value 0.000-0.190); (blue) admixture individuals (Q-value 0.191-0.810). Sample: (O) archival Sella; $(\square)$ contemporary Sella; $(\Delta)$ Scottish broodstocks samples showed intermixing with each other, the analyses mostly separated the archival sample (with higher intrapopulation diversity and absence of introgression) from the admixed contemporary sample.

\subsection{Estimates of census size, effective number of breeders, effective population size and their ratio to census size}

$N_{c}$ values revealed the strong decrease in this parameter in the River Sella over the 5 compared decades (Table 4). Our demographic analyses and interpretations were robust to delete-one jack-knifing of each of our analysed loci. The effective number of breeders estimated using the linkage disequilibrium method $\left(N b_{\mathrm{LD}}\right)$ also showed the same decreasing tendency (Table 4). The $\mathrm{Nb}_{\text {Adj }}$ values were nearly $8 \%$ lower than the non-adjusted ones and varied between 812 and 180. The same decreasing pattern was found in $\mathrm{Ne}_{\text {Adj, }}$ but the values were significantly smaller than the census size calculated from the rod catches.

The contribution of mature parr to reproduction was assessed considering a mean of 8 mature male parr per spawning female, in accordance with field studies from Iberian populations (Martínez et al. 2000). The contribution of mature male parr was considered to increase Ne by 1.5 to 2.2 times in Iberian populations. However, these appear to be maximum values because individual variations in reproductive success were not considered (Garant et al. 2000).

We also estimated $N b_{\text {SIB }}$ with the sibship method (Wang 2009), assuming random mating given that our samples are in Hardy-Weinberg equilibrium. The ob-

Table 4. Estimates of census size ( $N_{\mathrm{C}}, 20-40 \%$; see Section 2.3), effective number of breeders using the linkage disequilibrium approach $\left(N \mathrm{~b}_{\mathrm{LD}}\right)$ and the sibship approach $\left(N \mathrm{~b}_{\mathrm{SIB}}\right)$, adjusted number of breeders $\left(N \mathrm{~b}_{\mathrm{Adj}}\right)$, adjusted effective size $\left(N e_{\text {Adj }}\right)$, and the effective size ratios $N b_{\text {Adj }} / N_{C}$ and $N e_{\text {Adj }} / N_{C}$ for the archival and contemporary Atlantic salmon samples from the River Sella. $95 \%$ CI in parentheses

\begin{tabular}{|lcccccccc|}
\hline Sample & Caught & $\begin{array}{c}N \mathrm{~N} \\
(20-40 \%)\end{array}$ & $\begin{array}{c}N b_{\mathrm{LD}} \\
(\mathrm{CI} 95 \%)\end{array}$ & $\begin{array}{c}N b_{\mathrm{SIB}} \\
(\mathrm{CI} 95 \%)\end{array}$ & $\begin{array}{c}N b_{\mathrm{Adj}} \\
(\mathrm{CI} 95 \%)\end{array}$ & $\begin{array}{c}N \mathrm{e}_{\mathrm{Adj}} \\
(\mathrm{CI} 95 \%)\end{array}$ & $\begin{array}{c}N b_{\mathrm{Adj}} / N \mathrm{NC} \\
(20-40 \%)\end{array}$ & $\begin{array}{c}N \mathrm{e}_{\mathrm{Adj}} / N \mathrm{C} \\
(20-40 \%)\end{array}$ \\
\hline $\begin{array}{l}\text { Archival } \\
\text { sample }\end{array}$ & 1204 & $3010-6021$ & $\begin{array}{c}884 \\
(377-\infty)\end{array}$ & $\begin{array}{c}486 \\
(392-619)\end{array}$ & $\begin{array}{c}812 \\
(346-\infty)\end{array}$ & $\begin{array}{c}1535 \\
(654-\infty)\end{array}$ & $0.13-0.27$ & $0.26-0.51$ \\
$\begin{array}{l}\text { Contemporary } \\
\text { sample }\end{array}$ & 266 & $664-1329$ & $\begin{array}{c}176 \\
(115-502)\end{array}$ & $(43-92)$ & $(106-464)$ & $(200-877)$ & $0.14-0.27$ & $0.23-0.46$ \\
\hline
\end{tabular}


tained values were significant lower than those obtained with the LD method, probably due to the fact that the LD method underestimates Ne in large populations when sampling effort is limited, which could be our case, since its accuracy relies on the proportion of the population sampled (Ferchaud et al. 2016). Nevertheless, both estimates showed a similar and very pronounced decline (77 to $88 \%$ ) in the effective population size over time; this decline coincides with the decrease observed in salmon catches.

The estimated ratio between $N_{\mathrm{Adj}}$ and $\mathrm{NC}_{\mathrm{C}}$ did not show any temporal variation, with a mean value of 0.20 . Likewise, the estimated ratio of $\mathrm{Ne}_{\text {Adj }} / \mathrm{NC}_{\mathrm{C}}$ based only on adult censuses without taking migration into account, did not change between temporal samples (0.26 to 0.51$)$.

\section{DISCUSSION}

This study encompasses one of the largest temporal analyses of Atlantic salmon from the Iberian Peninsula to date. Archival scales of Atlantic salmon were collected in the 1950s prior to stocking practices, and we have used them as source material for a temporal comparison with contemporary samples from the 2000s to assess the relative status of current salmon populations in the River Sella, one of the rivers with a more pristine habitat within the southernmost distribution of the species. The Atlantic salmon population from the River Sella was recipient of 687100 foreign alevins introduced from Scotland between 1981 and 1992 (Hórreo et al. 2011a, 2014b).

Our results indicate a deterioration of the River Sella population, since 3 main changes can be observed: (1) the loss of native and distinctive alleles, (2) introgression in the contemporary River Sella sample, and (3) a reduction in the effective number of breeders and effective population size. The very low values of effective size in the contemporary population, together with the deleterious synergistic effects between genetic drift and high introgression rates, emerge as a severe threat to the long-term conservation of the native salmon population. We hypothesise that these genetic modifications are largely attributable to long-term stocking practices. The introduction of foreign stocks of salmon into the affected rivers was intended to counteract human impacts and the rapid decline of populations (Campos et al. 2008). We can now say that these measures, which lacked sufficient genetic knowledge, not only failed in their purpose of increasing population numbers but also introduced a new element of genetic change to pop- ulations: the presence of non-adapted individuals with new alleles (Ciborowski et al. 2007, Le Cam et al. 2015).

\subsection{Genetic variation and introgression analysis}

Loss of original alleles is not commonly reported in Atlantic salmon populations, but, for instance, the nearly extinct population in the River Skjern (Denmark) showed a significant decrease in the number of alleles over $60 \mathrm{yr}$ (Nielsen et al. 1997). Moreover, Ribeiro et al. (2008) found a loss of 7 alleles over $5 \mathrm{yr}$ in the River Eo, northern Spain, which they attributed to immigration, sampling strategy or, less likely, mutation events. However, a similar analysis carried out in several northwestern Spanish rivers, comparing scale collections from 1950-1960 and modern samples from 1997-2004 did not find any loss of original alleles (Saura et al. 2006), and the authors concluded that average heterozygosity and allelic richness were very similar in the modern and old samples. In contrast, our study that considers a $50 \mathrm{yr}$ lapse of time seems to provide good evidence of such a change in the stocked populations of the River Sella: the loss of 2 formerly frequent alleles (5.72 and $4.78 \%$ frequency in the archival sample), a large decrease (range: $4.12-15.24 \%$ ) in the frequency of 14 alleles (originally occurring with at least $4 \%$ frequency), the occurrence of 3 new alleles (with at least $4 \%$ frequency) in the contemporary sample, and a large increase (range: 4.66-8.78\%) in the frequency of 10 alleles already present in the past.

Domestic Atlantic salmon strains were introduced into the Sella population as shown by the $38 \%$ putative non-native Scottish broodstock in the contemporary sample compared to the archival non-introgressed one. This indicates that foreign individuals released over decades, who succeeded in introgression with local salmon, introduced new alleles into the natural populations (see also Martínez et al. 2001, Hórreo et al. 2014b). Furthermore, stocking with juvenile salmon born in hatcheries may alter life-history traits of adaptive significance (Le Cam et al. 2015), as their relative reproductive success is nearly half that of wild-born fish (Milot et al. 2013).

Perrier et al. (2013b) found a 10 to 25 times lower survival of stocked fish relative to wild specimens, which might suggest that genetic introgression due to stocking practices may not be a relevant problem. Anyway, stocked precocious males always have a great opportunity to elevate maladaptive gene flow, even if they do not survive to the post-smolt stage. 
However, the genetic deterioration found here in the River Sella rules out the idea suggested by Perrier et al. (2013b), because any introgression of foreign genetic material causing a reduction in genetic diversity and/or a loss of unique genetic combinations can be a serious threat, since salmon populations are characterized by strong adaptations to local conditions (García de Leániz et al. 2007).

Our results provide evidence that heterozygosity was high and stable and did not differ between temporal samples. However, the contemporary sample presented a higher allelic richness due to the occurrence of new foreign alleles. These 2 temporal samples showed high polymorphism values and no signs of old or recent bottlenecks.

In COLONY analyses, the archival sample showed 166 full-sib families of typically 1 individual, with the exception of 1 family of 3 individuals and 4 of 2 . Likewise, the contemporary sample was composed of 79 full-sib families of generally 1 or 2 individuals.

In conclusion, the increase in allelic richness over time in the River Sella, the loss or decrease in frequency of native alleles, and the appearance or increase in frequency of other alleles could be the result of a genetic introgression process due to the stocking made in the 1980s, mainly with Scottish salmon. Similar results have been found in studies with microsatellites in nearby rivers, such as the Esva and Cares (Ayllón et al. 2006), and in more remote locations, such as the River Nivelle in France (Martínez et al. 2001) and other French rivers (Perrier et al. 2013a). Other genetic markers such as mitochondrial DNA have also revealed an increase in genetic diversity in salmon populations from the Iberian Peninsula due to the introduction of foreign haplotypes (Ciborowski et al. 2007).

\subsection{Estimates of census size $(\mathrm{Nc})$ and effective number of breeders $(\mathrm{Nb})$, effective population size $(\mathrm{Ne})$ and their ratio to $\mathrm{Nc}$}

The present study also represents an attempt to document the long-term possible variation in number of breeders, effective population size and their ratio to census size in Atlantic salmon, before and after the abrupt decline of the population.

The $N b_{\mathrm{LD}}$ values decreased by $78 \%$ over time (884 in the archival and 176 in the contemporary sample) (Table 4). These values are within the wide range observed in Canadian rivers (42-3784) by Palstra et al. (2009), Johnstone et al. (2013) and Perrier et al. (2016). $N b_{\text {SIB }}$ also showed an abrupt change in our
50 yr analysis (486 in the archival and 62 in the contemporary sample), with very low values in the contemporary sample and a decrease of $87 \%$. Similarly, low values were recently found in the River Nivelle, France (23-76, in 2004-2014) by Bacles et al. (2018), and in 10 Canadian rivers (46-186, in 2010-2014) by Ferchaud et al. (2016). Moreover, $N b_{\text {SIB }}$ estimates in our study may be biased towards low values due to overlapping generations. An alternative explanation already put forward for Atlantic salmon (Johnstone et al. 2013) might be that the sibship method implemented in COLONY is more likely to be biased when sample sizes are small. This may result in an underestimation of $\mathrm{Nb}$ values when studying large populations with small sample sizes that do not accurately reflect the entire sibship network (Wang 2016). However, the estimated $\mathrm{Ne}_{\text {Adj }}$ for each year seems to be a better estimate of the LD within the cohort. In addition, to avoid bias due to overlapping generations using the LD method, the estimates of $\mathrm{Nb}$ and $\mathrm{Ne}$ have been corrected according to Waples et al. (2014), incorporating 3 life-history traits of the Sella population.

After adjusting $N b_{\mathrm{LD}}$ to consider overlapping generations, $N b_{\text {Adj }}$ showed the same downward trend (812 in the archival and 180 in the contemporary sample). The $N \mathrm{Ne}_{\text {Adj }}$ estimated from $N \mathrm{~b}_{\mathrm{LD}}$ in our $50 \mathrm{yr}$ analysis also showed an abrupt change (1535 in the archival and 341 in the contemporary sample), with a decrease of $78 \%$. The $\mathrm{Ne}_{\text {Adj }}$ estimates in the present study are within the range observed by other authors in Atlantic salmon populations in 10 Canadian rivers (124-2976; Ferchaud et al. 2016), and also compare well with Ne values in Canada (443-1697; Palstra et al. 2007), Russia (26-8318; Ozerov et al. 2012), France (48-1289; Perrier et al. 2013a) and Spain (3796; Hórreo et al. 2011b).

The contemporary sample showed a relatively low $\mathrm{Ne}_{\text {Adj }}$, but this was higher than the proposed specific minimum threshold for Atlantic salmon $(\mathrm{Ne}=95)$. Moreover, the value was also higher than the proposed threshold above which short-term inbreeding depression can be minimized $(\mathrm{Ne}=100$; Frankham et al. 2014). Therefore, our findings could suggest that negative inbreeding effects may not be a major threat to this population. However, the contemporary sample had an $\mathrm{Ne}_{\text {Adj }}$ estimate under the threshold where no assurance can be given that the evolutionary potential is preserved in the long term $(\mathrm{Ne}=$ 1000; Frankham et al. 2014).

The $N_{\text {Adj }} / N_{c}$ ratio (0.23-0.51) estimates obtained in this study did not show temporal variation. The $\mathrm{Ne}_{\text {Adj }} / N_{\mathrm{C}}$ ratio values in the River Sella are in agree- 
ment with those found by Consuegra et al. (2005) (0.18-0.54) in 4 contemporary samples from northern Spain.

The lack of relationship between the $N_{\mathrm{Adj}} / N \mathrm{C}$ ratio and $N c$ found in the River Sella could be explained by the fact that mechanisms of genetic compensation may counteract $\mathrm{Ne}_{\text {Adj }}$ reductions and thus increase $N_{\mathrm{Adj}} / N \mathrm{C}$ (Palstra \& Ruzzante 2008). This genetic compensation can be considered to produce a buffering effect against the loss of genetic diversity at low Nc.

Similarly, the $N \mathrm{~b}_{\mathrm{Adj}} / \mathrm{NC}_{\mathrm{C}}$ ratio $(0.13-0.27)$ did not show any significant temporal variation, despite the sharp decline in Nc. Moreover, the contribution to reproduction of fish that may not have been considered while calculating $N \mathrm{c}$ may produce a similar $N \mathrm{bb}_{\mathrm{Adj}} / N_{\mathrm{C}}$ ratio while Nc decreases. In southern European populations, where environmental conditions are particularly limiting for salmon, species can make use of alternative mating strategies to increase their reproductive success. In Atlantic salmon, this alternative strategy is specific to males, which can reach maturity and spawn in freshwater without having migrated to sea. Saura et al. (2008) observed that mature parr can increase the effective population size up to 2 or 3 times. A possible explanation is that warmer temperatures allow a faster growth in body size and weight, and this is correlated with reproductive success (Martínez et al. 2000, García-Vázquez et al. 2001). These precocious mature parr can contribute $60 \%$ of the total paternity (Saura et al. 2008) and the participation of male parr throughout the generations creates a buffer effect on the population size, compensating a skewed sex ratio between adults (Johnstone et al. 2013). Consequently, if the relative contribution of mature male parr to $\mathrm{Nb}_{\text {Adj }}$ rises in smaller populations or during years with reduced numbers of anadromous fish returning to the river, the $\mathrm{Nb}_{\mathrm{Adj}} / N_{\mathrm{c}}$ ratio is expected to rise or not change while $N_{c}$ decreases. Moreover, compensation mechanisms by which the $\mathrm{Nb}_{\text {Adj }} / N_{\mathrm{C}}$ ratio decreases less than would be expected during years with reduced Nc may be of prime importance in a conservation context.

\subsection{Conclusions}

An Atlantic salmon population from one of the main rivers in their southernmost distribution has suffered a substantial change over the last 5 decades, with low $\mathrm{Ne}$ and $\mathrm{Nb}$ and a steep population decline. Whether by direct impacts such as stocking practices and overfishing, or by indirect effects such as climate change, anthropogenic influence is the main threat for the species. It is difficult to assess which factor is the most influential or how they will shape populations in the future, but what seems clear is that the biology of this species is changing to adapt to the harsh conditions that man has imposed in such a short evolutionary period. However, current genetic status in the River Sella presents a relevant genetic diversity with a higher number of alleles than in the past and a similar $H_{\mathrm{e}}$ level. Small populations are expected to suffer under the detrimental effects of genetic drift because it leads to loss of genetic diversity. Despite the appearance of higher allelic richness, it is important to determine where those alleles came from and why native alleles have been replaced or have disappeared. The foreign stocks introduced over decades are one of the main reasons for these allele frequency alterations, as well as the complex shifting in the life-history traits of the species. Mature parr may contribute to the increase in genetic variability and enlarge the effective population size. In summary, Atlantic salmon is a resilient species trying to survive in the adverse conditions that man has imposed over decades. Stocking has been pernicious, and its effects add to those of climate change, being the main human pressures affecting salmon biology and the integrity of the species' genome. Our findings in southern Europe could be extended to other areas where declining salmon populations have been managed through similar stocking practices.

Acknowledgements. This study was funded by the Spanish Ministry of Economy and Competitiveness through the research project CGL2012-36049/BOS. Contemporary samples were provided by Jerónimo de la Hoz (Environmental Agency, Regional Government of Asturias, Spain). We are very grateful to Dr. John Gilbey, who kindly provided us with the microsatellite baseline generated by the SALSEA-Merge Project (www.nasco.int/sas/salseamerge.htm). All field and laboratory procedures complied with the current laws of Spain. J.L.H. was supported by a Spanish MINECO Juan de la Cierva-Incorporación postdoctoral grant (ref. IJCI-201523618). The authors have no conflicts of interest to declare.

\section{LITERATURE CITED}

Almodóvar A, Nicola GG, Elvira B, García-Marín JL (2006) Introgression variability among Iberian brown trout Evolutionary Significant Units: the influence of local management and environmental features. Freshw Biol 51: 1175-1187

Almodóvar A, Nicola GG, Ayllón D, Elvira B (2012) Global warming threatens the persistence of Mediterranean brown trout. Glob Change Biol 18:1549-1560

Almodóvar A, Ayllón D, Nicola GG, Jonsson B, Elvira B (2019) Climate-driven bio-physical changes in feeding 
and breeding environments explain the decline of southernmost European Atlantic salmon populations. Can J Fish Aquat Sci 76:1581-1595

Ayllón F, Martínez JL, García-Vázquez E (2006) Loss of regional population structure in Atlantic salmon, Salmo salar L., following stocking. ICES J Mar Sci 63:1269-1273

Bacles CFE, Bouchard C, Lange F, Manicki A, Tentelier C, Lepais $O$ (2018) Estimating the effective number of breeders from single parr samples for conservation monitoring of wild populations of Atlantic salmon Salmo salar. J Fish Biol 92:699-726

Belkhir K, Borsa P, Chikhi L, Raufaste N, Bonhomme F (2004) GENETIX 4.05, logiciel sous Windows TM pour la génétique des populations. Laboratoire Génome, Populations, Interactions, CNRS UMR 5171, Université de Montpellier II, Montpellier

* Campos JL, Posada D, Morán P (2008) Introgression and genetic structure in northern Spanish Atlantic salmon (Salmo salar L.) populations according to mtDNA data. Conserv Genet 9:157-169

Ciborowski KL, Consuegra S, García de Leániz C, Wang J, Beaumont MA, Jordan WC (2007) Stocking may increase mitochondrial DNA diversity but fails to halt the decline of endangered Atlantic salmon populations. Conserv Genet 8:1355-1367

Consuegra S, Verspoor E, Knox D, García de Leániz C (2005) Asymmetric gene flow and the evolutionary maintenance of genetic diversity in small, peripheral Atlantic salmon populations. Conserv Genet 6:823-842

Dąbrowski MJ, Pilot M, Kruczyk M, Żmihorski M, Umer HM, Gliwicz J (2014) Reliability assessment of null allele detection: inconsistencies between and within different methods. Mol Ecol Resour 14:361-373

Do C, Waples RS, Peel D, Macbeth GM, Tillet BJ, Ovenden JR (2014) NeEstimator V2: Re-implementations of software for the estimation of contemporary effective population size $\left(N_{e}\right)$ from genetic data. Mol Ecol Resour 14: 209-214

Earl DA, von Holdt BM (2012) STRUCTURE HARVESTER: a website and program for visualizing STRUCTURE output and implementing the Evanno method. Conserv Genet Resour 4:359-361

Estoup A, Largiader CR, Perrot E, Chourrout D (1996) Rapid one-tube extraction for a reliable PCR detection of fish polymorphic markers and transgenes. Mol Mar Biol Biotechnol 5:295-298

Excoffier L, Lischer HEL (2010) Arlequin suite ver 3.5: a new series of programs to perform population genetics analyses under Linux and Windows. Mol Ecol Resour 10: 564-567

Ferchaud AL, Perrier C, April J, Hernandez C, Dionne M, Bernatchez L (2016) Making sense of the relationships between $\mathrm{Ne}, \mathrm{Nb}$ and $\mathrm{Nc}$ towards defining conservation thresholds in Atlantic salmon (Salmo salar). Heredity 117: 268-278

Frankham R, Bradshaw CJA, Brook BW (2014) Genetics in conservation management: revised recommendations for the 50/500 rules, red list criteria and population viability analyses. Biol Conserv 170:56-63

₹ Garant D, Dodson JJ, Bernatchez L (2000) Ecological determinants and temporal stability of the within-river population structure in Atlantic salmon (Salmo salar L.). Mol Ecol 9:615-628

* García de Leániz C, Fleming IA, Einum S, Verspoor E and others (2007) A critical review of adaptive genetic varia- tion in Atlantic salmon: implications for conservation. Biol Rev Camb Philos Soc 82:173-211

*García-Vázquez E, Morán P, Martínez JL, Pérez J, de Gaudemar B, Beall E (2001) Alternative mating strategies in Atlantic salmon and brown trout. J Hered 92: 146-149

*Garza JC, Williamson EG (2001) Detection of reduction in population size using data from microsatellite loci. Mol Ecol 10:305-318

* Gilbert KJ, Whitlock MC (2015) Evaluating methods for estimating local effective population size with and without migration. Evolution 69:2154-2166

*Gilbey J, Coughlan J, Wennevik V, Prodöhl P and others (2018) A microsatellite baseline for genetic stock identification of European Atlantic salmon (Salmo salar L.). ICES J Mar Sci 75:662-674

KGlover KA, Quintela M, Wennevik V, Besnier F, Sørvik AGE, Skaala $\varnothing$ (2012) Three decades of farmed escapees in the wild: a spatio-temporal analysis of Atlantic salmon population genetic structure throughout Norway. PLOS ONE 7:e43129

Glover KA, Solberg MF, McGinnity P, Hindar K and others (2017) Half a century of genetic interaction between farmed and wild Atlantic salmon: status of knowledge and unanswered questions. Fish Fish 18:890-927

Goudet J (1995) FSTAT (Version 1.2): A computer program to calculate F-statistics. J Hered 86:485-486

* Hórreo JL, Machado-Schiaffino G, Ayllón F, Griffiths AM, Bright D, Stevens JR, García-Vázquez E (2011a) Impact of climate change and human-mediated introgression on southern European Atlantic salmon populations. Glob Change Biol 17:1778-1787

*Hórreo JL, Machado-Schiaffino G, Griffiths AM, Bright D, Stevens JR, García-Vázquez E (2011b) Atlantic salmon at risk: apparent rapid declines in effective population size in southern European populations. Trans Am Fish Soc 140:605-610

*Hórreo JL, de la Hoz J, Pola IG, Machado-Schiaffino G, García-Vázquez E (2012) Ecological and economic costs of supportive breeding: Atlantic salmon (Salmo salar) as a case study. Aquaculture 356-357:1-6

* Hórreo JL, Turrero P, Pérez J, García-Vázquez E (2014a) Long-term species balance in sympatric populations: implications for Atlantic salmon and brown trout. Front Biogeogr 6:111-118

*Hórreo JL, Machado-Schiaffino G, Griffiths AM, Bright D, Stevens JR, García-Vázquez E (2014b) Long-term effects of stock transfers: synergistic introgression of allochthonous genomes in salmonids. J Fish Biol 85:292-306

*Jakobsson M, Rosenberg NA (2007) CLUMPP: a cluster matching and permutation program for dealing with label switching and multi-modality in analysis of population structure. Bioinformatics 23:1801-1806

Johnstone DL, O'Connell MF, Palstra FP, Ruzzante DE (2013) Mature male parr contribution to the effective size of an anadromous Atlantic salmon (Salmo salar) population over 30 years. Mol Ecol 22:2394-2407

Jones OR, Wang J (2010) COLONY: a program for parentage and sibship inference from multilocus genotype data. Mol Ecol Resour 10:551-555

Jonsson B, Jonsson N (2009) A review of the likely effects of climate change on anadromous Atlantic salmon Salmo salar and brown trout Salmo trutta, with particular reference to water temperature and flow. J Fish Biol 75: 2381-2447 
Kalinowski ST, Taper ML (2006) Maximum likelihood estimation of the frequency of null alleles at microsatellite loci. Conserv Genet 7:991-995

Kalinowski ST, Taper ML, Marshall TC (2007) Revising how the computer program CERVUS accommodates genotyping error increases success in paternity assignment. Mol Ecol 16:1099-1106

Ke Cam S, Perrier C, Besnard AL, Bernatchez L, Evanno G (2015) Genetic and phenotypic changes in an Atlantic salmon population supplemented with non-local individuals: a longitudinal study over 21 years. Proc R Soc B 282: 20142765

Lehnert SJ, Kess T, Bentzen P, Kent MP and others (2019) Genomic signatures and correlates of widespread population declines in salmon. Nat Commun 10:2996

*Martínez JL, Morán P, Pérez J, De Gaudemar B, Beall E, García-Vázquez E (2000) Multiple paternity increases effective size of southern Atlantic salmon populations. Mol Ecol 9:293-298

* Martínez JL, Dumas J, Beall E, García-Vázquez E (2001) Assessing introgression of foreign strains in wild Atlantic salmon populations: variation in microsatellites assessed in historic scale collections. Freshw Biol 46:835-844

Milot E, Perrier C, Papillon L, Dodson JJ, Bernatchez L (2013) Reduced fitness of Atlantic salmon released in the wild after one generation of captive breeding. Evol Appl 6:472-485

Nicola GG, Elvira B, Jonsson B, Ayllón D, Almodóvar A (2018) Local and global climatic drivers of Atlantic salmon decline in southern Europe. Fish Res 198: 78-85

Nielsen EE, Hansen MM, Loeschcke V (1997) Analysis of microsatellite DNA from old scale samples of Atlantic salmon: a comparison of genetic composition over sixty years. Mol Ecol 6:487-492

Nielsen EEG, Bach LA, Kotlicki P (2006) HYBRIDLAB (version 1.0): a program for generating simulated hybrids from population samples. Mol Ecol Notes 6:971-973

O'Reilly PT, Hamilton LC, McConnell SK, Wright JM (1996) Rapid analysis of genetic variation in Atlantic salmon (Salmo salar) by PCR multiplexing of dinucleotide and tetranucleotide microsatellites. Can J Fish Aquat Sci 53: 2292-2298

* Ozerov MY, Veselov AE, Lumme J, Primmer CR (2012) 'Riverscape' genetics: river characteristics influence the genetic structure and diversity of anadromous and freshwater Atlantic salmon (Salmo salar) populations in northwest Russia. Can J Fish Aquat Sci 69:1947-1958

Palstra FP, Ruzzante DE (2008) Genetic estimates of contemporary effective population size: what can they tell us about the importance of genetic stochasticity for wild population persistence? Mol Ecol 17:3428-3447

Palstra FP, O'Connell MF, Ruzzante DE (2007) Population structure and gene flow reversals in Atlantic salmon (Salmo salar) over contemporary and long-term temporal scales: effects of population size and life history. Mol Ecol 16:4504-4522

Palstra FP, O'Connell MF, Ruzzante DE (2009) Age structure, changing demography and effective population size in Atlantic salmon (Salmo salar). Genetics 182: 1233-1249

Paterson S, Piertney SB, Knox D, Gilbey J, Verspoor E (2004) Characterization and PCR multiplexing of novel highly variable tetranucleotide Atlantic salmon (Salmo salar L.) microsatellites. Mol Ecol Notes 4:160-162
Peakall R, Smouse PE (2012) GenAlEx 6.5: genetic analysis in Excel. Population genetic software for teaching and research - an update. Bioinformatics 28:2537-2539

Peery MZ, Kirby R, Reid BN, Stoelting R and others (2012) Reliability of genetic bottleneck tests for detecting recent population declines. Mol Ecol 21:3403-3418

* Perrier C, Guyomard R, Baglinière JL, Nikolic N, Evanno G (2013a) Changes in the genetic structure of Atlantic salmon populations over four decades reveal substantial impacts of stocking and potential resiliency. Ecol Evol 3: 2334-2349

* Perrier C, Baglinière JL, Evanno G (2013b) Understanding admixture patterns in supplemented populations: a case study combining molecular analyses and temporally explicit simulations in Atlantic salmon. Evol Appl 6: 218-230

* Perrier C, April J, Cote G, Bernatchez L, Dionne M (2016) Effective number of breeders in relation to census size as management tools for Atlantic salmon conservation in a context of stocked populations. Conserv Genet 17:31-44

* Piry S, Luikart G, Cornuet JM (1999) Computer note. BOTTLENECK: a computer program for detecting recent reductions in the effective size using allele frequency data. J Hered 90:502-503

Pritchard JK, Stephens M, Donnelly P (2000) Inference of population structure using multilocus genotype data. Genetics 155:945-959

* Ribeiro A, Morán P, Caballero A (2008) Genetic diversity and effective size of the Atlantic salmon Salmo salar L. inhabiting the River Eo (Spain) following a stock collapse. J Fish Biol 72:1933-1944

Kosenberg NA (2004) DISTRUCT: a program for the graphical display of population structure. Mol Ecol Notes 4: $137-138$

Rousset F (2008) Genepop'007: a complete reimplementation of the Genepop software for Windows and Linux. Mol Ecol Resour 8:103-106

*Sánchez JA, Clabby C, Ramos D, Blanco G, Flavin F, Vázquez E, Powell R (1996) Protein and microsatellite single locus variability in Salmo salar L. (Atlantic salmon). Heredity 77:423-432

* Saura M, Caballero P, Caballero A, Morán P (2006) Genetic variation in restored Atlantic salmon (Salmo salar L.) populations in the Ulla and Lérez rivers, Galicia, Spain. ICES J Mar Sci 63:1290-1296

* Saura M, Caballero A, Caballero P, Morán P (2008) Impact of precocious male parr on the effective size of a wild population of Atlantic salmon. Freshw Biol 53: 2375-2384

* Schindler DE, Hilborn R, Chasco B, Boatright CP, Quinn TP, Rogers LA, Webster MS (2010) Population diversity and the portfolio effect in an exploited species. Nature 465 : $609-612$

* Slettan A, Olsaker I, Lie Ø (1995) Atlantic salmon, Salmo salar, microsatellites at the SSOSL25, SSOSL85, SSO SL311, SSOSL417 loci. Anim Genet 26:281-282

Slettan A, Olsaker I, Lie Ø (1996) Polymorphic Atlantic salmon, Salmo salar L., microsatellites at the SSOSL438, SSOSL439 and SSOSL444 loci. Anim Genet 27:57-58

* Sylvester EVA, Wringe BF, Duffy SJ, Hamilton LC and others (2019) Estimating the relative fitness of escaped farmed salmon offspring in the wild and modelling the consequences of invasion for wild populations. Evol Appl 12:705-717

*Vähä JP, Primmer CR (2006) Efficiency of model-based 
Bayesian methods for detecting hybrid individuals under different hybridization scenarios and with different numbers of loci. Mol Ecol 15:63-72

Van Oosterhout C, Hutchinson WF, Wills DP, Shipley P (2004) Micro-checker: software for identifying and correcting genotyping errors in microsatellite data. Mol Ecol Notes 4:535-538

Verspoor E, Stradmeyer E, Nielsen J (eds) (2007) The Atlantic salmon: genetics, conservation and management. Blackwell, Oxford

Wang J (2009) A new method for estimating effective popu- lation sizes from a single sample of multilocus genotypes. Mol Ecol 18:2148-2164

* Wang J (2016) A comparison of single-sample estimators of effective population sizes from genetic marker data. Mol Ecol 25:4692-4711

Waples RS, Antao T, Luikart G (2014) Effects of overlapping generations on linkage disequilibrium estimates of effective population size. Genetics 197:769-780

WWF (2001) The status of wild Atlantic salmon: a river by river assessment. World Wide Fund for Nature, Washington, DC

\section{Appendix.}

Table A1. Genotype error rates and their $95 \%$ confidence interval (error rate, CI 95\%) of each locus for the archival and contemporary Atlantic salmon samples from the River Sella

\begin{tabular}{|c|c|c|}
\hline \multirow[t]{2}{*}{ Locus } & \multicolumn{2}{|c|}{ Error rate (CI $95 \%)$} \\
\hline & Archival sample & Contemporary sample \\
\hline Ssa197 & $0.009(0.000-0.029)$ & $0.004(0.000-0.018)$ \\
\hline Ssa202 & $0.029(0.009-0.166)$ & $0.013(0.001-0.050)$ \\
\hline SSOSL85 & $0.005(0.000-0.014)$ & $0.032(0.002-0.090)$ \\
\hline SSOSL311 & $0.022(0.000-0.025)$ & $0.009(0.000-0.026)$ \\
\hline SSOSL417 & $0.007(0.000-0.039)$ & $0.007(0.000-0.026)$ \\
\hline SSspG7 & $0.004(0.000-0.052)$ & $0.004(0.000-0.014)$ \\
\hline SSsp1605 & $0.013(0.000-0.085)$ & $0.016(0.000-0.033)$ \\
\hline SSsp2210 & $0.001(0.000-0.014)$ & $0.027(0.000-0.054)$ \\
\hline
\end{tabular}

Editorial responsibility: David Richardson, Norwich, UK
Submitted: March 27, 2019; Accepted: February 6, 2020

Proofs received from author(s): March 8, 2020 